\title{
STUDY OF ELECTROCHEMICAL PROPERTIES OF Li-ION BATTERIES \& ITS APPLICATIONS
}

\author{
S. Tolani \\ Department of Physics \\ St. Vincent Pallotti College of Engg. \& Tech., Nagpur-441108 \\ Email:smitatolani@gmail.com,smita_tolani@rediffmail.com
}

\begin{abstract}
:
Cycling performance of Li-ion cell was studied by using electrochemical impedance spectroscopy (EIS). The stability of uncoated copper $(\mathrm{Cu})$ foils and graphite-coated copper $(\mathrm{Cu}-\mathrm{C})$ foils in lithium-ion battery electrolytes were extensively studied in this paper. The electrochemical behavior and stability of the $\mathrm{Cu}$ foils and $\mathrm{Cu}-\mathrm{C}$ foils were studied. Cyclic voltammetry was used to study the redox behavior of the foils in the electrolyte solutions. The reduction of electrolyte and its effect on the oxidation of copper was also studied. Bulk electrolysis was used to quantitatively study the dissolution of the foils in dry electrolytes and in electrolytes doped with impurities of $\mathrm{H}_{2} \mathrm{O}$ or $\mathrm{HF}$. It was found that the graphite coating greatly influenced the redox behavior of the copper substrate and provided some protection to the copper from oxidation. Impurities increases the oxidation tendency of both $\mathrm{Cu}$ foils and $\mathrm{Cu}-\mathrm{C}$ foils and may influence the integrity of the $\mathrm{Cu}-\mathrm{C}$ foil electrode. A lithium-ion battery is a family of rechargeble battery types in which Lithium ions move from the negative electrode to the positive electrode during discharge, and back when charging. Li-ion batteries use anintercalated lithium compound as the electrode material, compared to the metallic lithium used in the non-rechargeble lithium battery.
\end{abstract}

Keywords : lithium-ion battery, Electrochemical Properties, Anode, Cathode

\section{INTRODUCTION:}

A number of papers have addressed the problem of the low temperature performance of Li-ion batteries [1-10]. Generally, both energy and power of the Li-ion batteries are substantially reduced as the temperature falls to below $-10^{\circ} \mathrm{C}$. It has been reported that at $-40^{\circ} \mathrm{C}$ a commercial 18650 Li-ion battery only delivered $5 \%$ of energy density and $1.25 \%$ of power density, as compared to the values obtained at $20^{\circ} \mathrm{C}$ [6]. In addition, 
significant differences in the cycling performance has been observed. At low temperatures, a Li-ion battery can be normally discharged, while the reverse charging process is rather difficult [2,4,9].Although the origin of low temperature phenomena are still under debate, they can be summarized as follows: (i) reduced ionic conductivity of the electrolyte and solid electrolyte interface (SEI) formed on the graphite surface [1,3,5], (ii) limited diffusivity of lithium ion within graphite [2,9], (iii) high polarization of the graphite anode, which isassociated with the former two factors [4,7], and (iv) substantially increased charge-transfer resistance on the electrolyte- electrode interfaces [8,10]. It should be noted that all the above conclusions were obtained from either Li-ion or Li. In this work, we used electrochemical impedance spectroscopy (EIS) to study impedance of the Li-ion battery and to evaluate its dependence on state-of-charge. Using the collected impedance data, we explained at low temperatures why charging of a fully discharged Li-ion cell is very difficult, and why its power and energy are lost substantially.

\section{Experimental:}

The electrolyte used was a 1.0m LiPF6 solution in a 3:7 (wt.) mixture of ethylene carbonate (EC) and ethyl methyl carbonate (EMC) with a water content of 10-15 ppm, as determined by Karl-Fisher titration. Standard graphite and cathode films, provided by SAFT America Inc., were dried at $110{ }^{\circ} \mathrm{C}$ under vacuum for $16 \mathrm{~h}$ before use. The cathode active material was a lithium nickel-based mixed oxide, hereafter called "cathode". Button cells with an electrode area of $0.97 \mathrm{~cm} 2$ were assembled as a testing vehicle in an argon-filled glove-box for the electrochemical measurements.

To ensure completion of the solid-state interface formation, all cells (both Li-ion full cells and Li half-cells) were cycled 10 times on a Maccor Series 4000 tester before electrochemical measurement was made. A Tenney 
Environmental Oven Series 942 was used to provide a constant temperature environment for the tests at various temperatures. Using a Maccor Series 4000 tester, discharge capacity was measured by first charging the cell to 4.2 Vat $20^{\circ} \mathrm{C}$ with a time limit of $3 \mathrm{~h}$, and then discharging to $2.5 \mathrm{~V}$ at a specific temperature. Current density for both charge and discharge processes was $0.5 \mathrm{~mA} / \mathrm{cm} 2$ (_0.5 Crate). To describe low temperature performance, we defined the ratio of the capacity at a specific temperature to the capacity obtained at $20^{\circ} \mathrm{C}$ as a "relative capacity", and the ratio of the resistances as a "relative resistance". Solartron SI 1287 Electrochemical Interface and SI 1260 Impedance/Gain-Phase Analyzer were adapted to determine the ionic conductivity of the electrolyte and to measure electrochemical impedance spectroscopy (EIS) of the cells. Before the impedance measurement was made, all cells were cycled 10 times to ensure completion of SEI formation. To assemble a symmetric cell, the electrodes were first cycled 10 times and ended at a specific state-of-charge (SOC) in Li half-cells, followed by re-assembling them into a symmetric cell in the glove-box. To ensure an identical SOC of the electrodes, the resultant symmetric cell was further electrically shorted for $2 \mathrm{~h}$ before impedance measurements were done. The ac impedance of the cell was potentiostatically measured by applying a dc bias with its value equal to the open circuit voltage $(\mathrm{OCV})$ of the cell and an ac oscillation of $10 \mathrm{mVover}$ the frequencies from $100 \mathrm{kHz}$ to $0.01 \mathrm{~Hz}$. The obtained spectra were fitted using ZView software (Scribner and Associates Inc.).

\section{Results and discussion}

\section{Low temperature cycling performance}

Fig. 1 compares discharge curves of a Li-ion cell at various temperatures. It is shown that with decreasing temperature, both the operating voltage and capacity are reduced. The decreased operating voltage can be 
ascribed to an increased electric polarization of the cell due to a decrease in the ionic conductivity of electrolyte and SEI

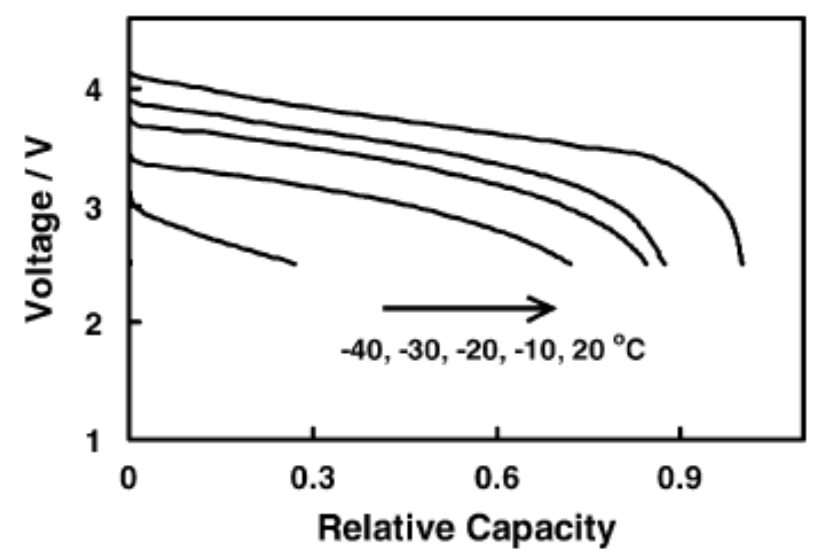

Fig. 1. Discharge curves of a Li-ion cell at various low temperatures.

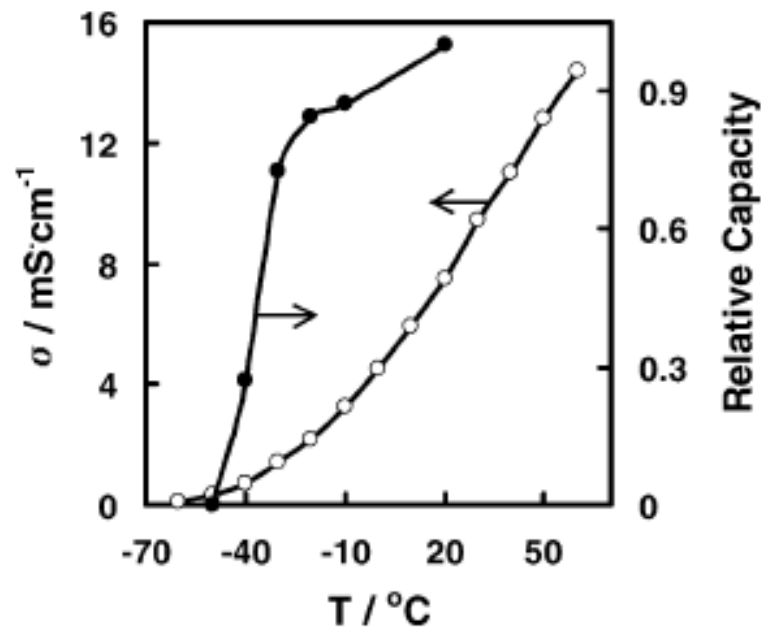

Fig. 2. Relative capacity of Li-ion cell and ionic conductivity of electrolyte as a function of temperature.

and to a slowdown of the cell electrochemical reactions. To observe the role of electrolytic conductivity in affecting cell performance, we plot electrolytic conductivity and relative capacity as a function of the temperature in Fig. 2. Due to participation of the highly compatible $\mathrm{PC}$, we find that even at $\_60^{\circ} \mathrm{C}$ EC crystallization from the electrolytic solution has been suppressed. In the testing temperature range, electrolytic conductivity is changed in a continuous 
manner, as indicated by a smooth curve in the conductivity-temperature plot (Fig. 2). However, there exists a rapid decrease in the relative capacity as the temperature falls to below $\_10^{\circ} \mathrm{C}$. Obviously, this rapid decrease in the relative capacity cannot be explained in terms of electrolytic conductivity.This fact reveals that electrolytic conductivity is not the only limitation in the low temperature performance of Li-ion batteries.

\section{EIS of the Li-ion cell}

A typical EIS of the Li-ion cells is shown in Fig. 3. In most of voltage range, the EIS of the Li-ion cells is composed of two partially overlapped semicircles and a straight slopping line at low frequency end. Such a pattern of the EIS can be fitted by an equivalent circuit shown in inset of Fig. 3. The $R \mathrm{~b}$ is bulk resistance of the cell, which reflects electric conductivity of the electrolyte, separator, and electrodes; Rsei and Csei are resistance and capacitance of the solid-state interface layer formed on the surface of the electrodes, which correspond to the semicircle at high frequencies; Rct and Cdl are faradic charge-transfer resistance and its relative double-layer capacitance, which correspond to the semicircle at medium frequencies; $W$ is the Warburg impedance related to a combination of the diffusional effects of lithium ion on the interface between the active material

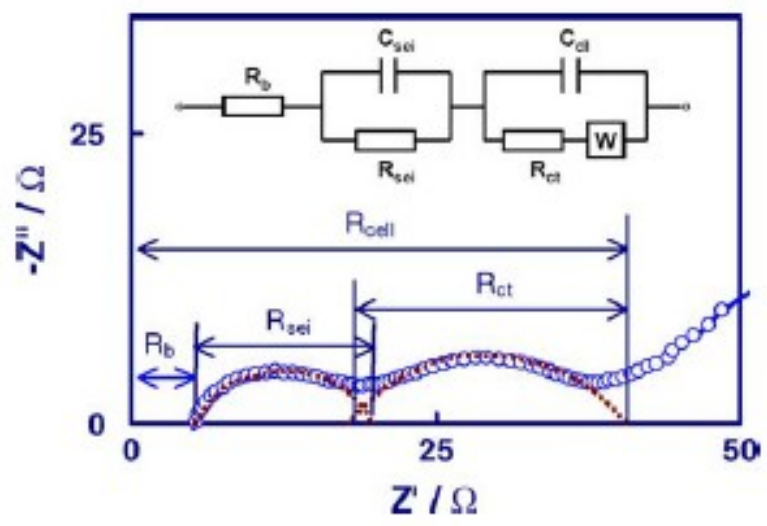

Fig 3: Typical EIS of the Li-ion cell and the equivalent circuit used to 
fit the EIS.

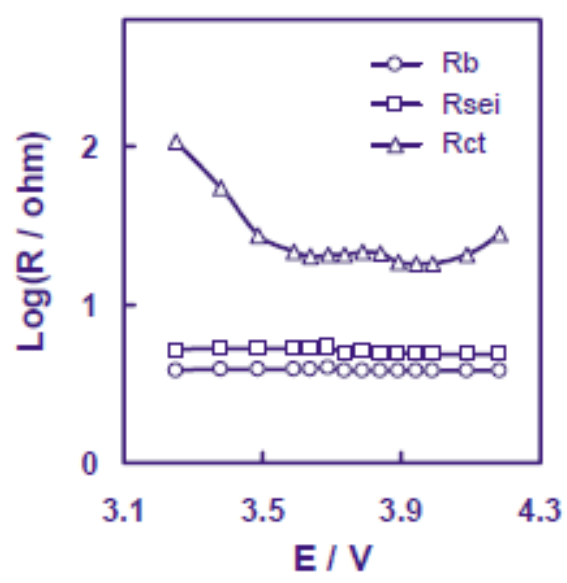

Fig 4: Voltage dependence of the $R b$, Rsei and Rct, measured from charge process.

particles and electrolyte, which is generally indicated by a straight sloping line at low frequency end. The combination of Rct and $W$ is called faradic impedance, which reflects kinetics of the cell reactions. Low Rct generally corresponds to a fast kinetics of the faradic reaction. For example, the Rct value can be used as a kinetic parameter to analyze the corrosion rate of metals, and there is a close correlation between the Rct and the apparent diffusivity of Li ions in the electrodes. Total resistance (Rcell) of the Li-ion cell, as shown in Fig. 3, is mainly contributed by the $R \mathrm{~b}, R$ sei, and Rct, but not a simply summation of these three individual values. In this work, the Rcell value was directly fitted from the EIS.

Applications: Applications of the commercially available Li-ion batteries are limited to near room temperature. When the temperature falls below $-20{ }^{\circ} \mathrm{C}$, both the power and energy of the Li-ion batteries are substantially lost [14-16]. More badly, the process of charging a fully discharged battery would become impossible [17-19]. It has been reported that at $-40 \circ \mathrm{C}$ a commercial 18650 Li-ion battery only retained $5 \%$ of energy density and $1.25 \%$ of power density, as compared to the 
values at $20{ }^{\circ} \mathrm{C}$ [14]. Therefore, improving low temperature performance has been an important subject of many researchers [19-24]. The successful improvement is mainly based on these two approaches: (i) formulating new solvent mixtures to lower freezing temperature of the liquid electrolytes [19-22], and (ii) replacing the existing LiPF6 salt with LiBF4 to reduce charge-transfer resistance of the batteries. Although both of the above approaches have led to improvement, the understanding of the poor low temperature performance is still under debate. The sources that were reported to affect low temperature performance can be summarized as follows: (i) reduced conductivity of the electrolyte and solid electrolyte interface on the electrode surface, (ii) limited diffusivity of lithium ions within graphite anode, (iii) high polarization of the graphite anode, which is related to the former two factors, and (iv) substantially increased charge-transfer resistance on the electrolyte-electrode interfaces Lithium primary batteries are the power source of choice for a range of medical implants. For cardiac demand pacemakers, the cell now in general use has a lithium anode with a conducting charge transfer complex formed by iodine and poly-2vinyl-pyridine as cathode. Li batteries are widely used in modern portable consumer electronics, including iPods, iPhone, cameras, camcorders, and cell phones. The diminished battery size versus power aspect of the lithium batteries has been credited with the smaller size of electronics we enjoy today.Lithium batteries find application in many long-life, critical devices, such as artificial pacemakers and other implantable electronic medical devices. These devices use specialized lithium-iodide batteries designed to last 15 or more years. But for other, less critical applications such as in toys, the lithium battery may actually outlast the device. In such cases, an expensive lithium battery may not be costeffective.Lithium batteries can be used in place of ordinary alkaline cells in many devices, such as clocks and cameras. Although they are more costly, lithium cells will provide much longer life, thereby minimizing 
battery replacement. However, attention must be given to the higher voltage developed by the lithium cells before using them as a drop-in replacement in devices that normally use ordinary zinc cells.

\section{Conclusion:}

The total resistance (Rcell) of the Li-ion cells is mainly composed of the bulk resistance $(R \mathrm{~b})$, solid-state interface resistance (Rsei), and chargetransfer resistance (Rct). Among these three resistances, the $R \mathrm{~b}$ and $R$ sei remain relatively unchanged with the cell voltage, while the Rct varies significantly.It is observed that the Rct increases most significantly as the temperature decreases. At low temperatures, the Rcell of the Li-ion cells is predominated by the Rct. The above observations reveal that at low temperatures the substantially high Rct results in the poor performance, and that the much larger Rct at the fully discharged state makes the charge process very difficult. It is because the Rct is closely associated with the kinetics of the cell reaction that the main limitation to the low temperature performance of the Li-ion batteries can be ascribed to the slow kinetics of the cell reaction. The demand for energy storage sources of high energy density has been growing rapidly recently as a result of the impetus of portable consumer electronics prevalence. Currently, more stringent requirements exist both in energy density andpower density of energy storage devices in the large applications, such as zero emission electric vehicles and satellites. Also, there is high demand for highperformance batteries. The secondary lithium-ion battery is a promising option to meet such demands because of its inherent outstanding characteristics. Li-ion batteries have become prevalent in small cell applications, such as cellular phones and notebook computers since their first introduction into the market in 1991 by Sony EnergeticThe proposal of the Li-ion battery for large applications appears to be a logical choice considering its characteristics. 
Many companies and government agencies are currently investigating Liion cells. However, there are still many problems to solve before their successful utility in such applications. For instance, long-term stability of cell components, heat control and safety issues, along with the better quality and costperformance requirements, are among the concerns. Research in this field has been very active and resulted in hundreds of publications and regular symposia at national and international conferences, such as the semi-annual meetings of the Electrochemical Society (ECS) and the annual meeting of the International Meeting on Lithium Batteries (IMLB). Compared to variety of previous battery compositions, Lithium is the way of the future - leading other elements in size to power density ratio.

\section{References}

M.C. Smart, B.V. Ratnakumar, S. Surampudi, (1999) J. Electrochem. Soc. 146486 .

C.K. Huang, J.S. Sakamoto, J. Wolfenstine, S. Surampudi, (2000) J. Electrochem. Soc. 147 : 2893.

E.J. Plichta, W.K. Behl, (2000) J. Power Sources 88 : 192.

H.P. Lin, D. Chua, M. Salomon, H.C. Shiao, M. Hendrickson, E.Plichta, S. Slane, (2001) Electrochem. Solid-State Lett. 4 : A71.

Ratnakumar, M.C. Smart, S. Surampudi, (2001) J. Power Sources 9798:137.

G. Nagasubramanian, (2001) J. Appl. Electrochem. 31:99.

C.S. Wang, A.J. Appleby, F.E. Little, (2002) J. Electrochem. Soc. 149 : A754.

S.S. Zhang, K. Xu, J.L. Allen, T.R. Jow, (2002) J. Power Sources 110 : 217. 
S.S. Zhang, K. Xu, T.R. Jow, (2002) Electrochim. Acta 48 : 241.

S.S. Zhang, K. Xu, T.R. Jow, (2002) Electrochem. Commun. 4 : 928.

M. Mohamedi, D. Takahashi, T. Itoh, I. Uchida, (2002) Electrochim. Acta $47: 3483$.

H. Ma, S. Chen, L. Niu, S. Zhao, S. Li, D. Li, (2002) J. Appl. Electrochem.32 : 65 .

S.S. Zhang, M.S. Ding, K. Xu, J. Allen, T.R. Jow, (2001) Electrochem.Solid-State Lett. 4 : A206.

G. Nagasubramanian, (2001) J. Appl. Electrochem. 31 : 99.

S.S. Zhang, K. Xu, T.R. Jow, (2003) J. Power Sources 115 :137.

J. Fan, (2003) J. Power Sources $117: 170$.

C.K. Huang, J.S. Sakamoto, J. Wolfenstine, S. Surampudi, (2000) J. Electrochem.Soc. 147 :2893.

H.P. Lin, D. Chua, M. Salomon, H.C. Shiao, M. Hendrickson, E. Plichta, S. Slane, (2001) Electrochem. Solid-State Lett. 4 : A71.

S.S. Zhang, K. Xu, T.R. Jow, (2002) Electrochim. Acta 48 : 241.

M.C. Smart, B.V. Ratnakumar, S. Surampudi, (1999) J. Electrochem. Soc. $146: 486$.

S. Herreyre, O. Huchet, S. Barusseau, F. Perton, J.M. Bodet, P. Biensan, (2001) J. Power Sources 97-98 : 576.

E.J. Plichta, W.K. Behl, (2000) J. Power Sources 88 : 192.

S.S. Zhang, K. Xu, J.L. Allen, T.R. Jow, (2002) J. Power Sources 110 : 217.

S.S. Zhang, K. Xu, T.R. Jow, (2003) J. Solid State Electrochem. 7 : 147. 